\title{
A New Neuroinformatics Approach to Optimize Diagnosis Cost in Neurology: An Operational Research Tool
}

\author{
https://doi.org/10.3991/ijoe.v15i06.10141 \\ Mohammad Rashid Hussain $(\bowtie)$ \\ King Khalid University, Abha, Saudi Arabia \\ humohammad@kku.edu.sa \\ Mohammad Equebal Hussain \\ Suresh Gyan Vihar University, Jaipur, India
}

\begin{abstract}
Cost optimization approach of operational research is a predictive power and economy of compactness that is applied to solve specific clinical needs relevant to healthcare cost reduction. Technology helps the healthcare management, decision making, and policy that we have implemented in the interest of improving quality of patient care and treatment outcomes, thereby reducing costs and improving efficiency. The treatment cost of brain tumor is high. Sometimes, cost becomes a problem for individuals to get their complete treatment, which makes their health at risk and may lead to higher cost in future. Here we address neuroinformatics approach to optimize diagnosis cost in neurology through an operational research tool (optimization) on how the diagnosis cost of neuro-patient can optimize. In this context, we introduce a new and unique optimization approach in healthcare, yet what we are clearly lacking for applying applications of operational tools to translate this understanding to the different level to apply the concept in healthcare. The costs of treatment achieved by three standard initial basic feasible solutions (IBFS) methods (North-west corner method, Minimum cost method, Vogel's approximation method) are 763, 763, and 779. The optimal solution is 761, and three random tests (RT's) are 826, 783, and 788. Optimal solution provided an overall difference in treatment cost with IBFS 2, 2, 18 and with RT's 65, 22, and 27. These results establish the basis for a deliberate integration of operational research tools and neuroscience into diagnosis of cost optimization mechanisms for neuro- patient.
\end{abstract}

Keywords - Cost optimization; stepping stone method; Modified distribution method; linear programming problem (LPP) ; Initial Basic Feasible Solution (IBFS); Random Tests (RT's); Neuroinformatics 


\section{Introduction}

Recent years have witnessed the intensifying corrosion of the treatment cost optimization predominance to the benefits of other approach in healthcare (e.g., In China, 390 people in a million are suffering from lung tuberculosis, which is the $10 \%$ of Globe TB rate). The Chinese govt. aims to minimize this rate to 163 people per million and stabilize it by 2050 [1]. Another major disease is lung cancer its ratio is also high and the survival rate of people likely to be 5 years with rate of $18.1 \%$ based on 2007-2013 SEER database [2]. One of the optimization approach have been introduced in output of convolution layer of CNN's to optimize and accelerate the training rate of deep network after additional information of connections [3]. Segmental fine-tuning provides a computer aided diagnosis, which provides an overall accuracy of $82 \%$ which other traditional TL achieved $70 \%$ to $74 \%$ [4].

Historical development, planning, optimization, and design making application of OR models in healthcare for public health are discussed in [5]. [6] Discusses the clinical problems, methods to optimize a system, and software facilitates the problem design. The concept of Queuing theory of operation research has been applied to reduce the patients waiting time by applying Monte Carlo modeling method [7]. To manage and control the patients waiting list of radiotherapy treatment, optimal scheduling strategy have been introduced [8]. To maximize the utilization of devices and minimize the outpatient waiting time, real life optimized model have been introduced to improve the work efficiency [9]. In healthcare planning and management systems, the responsibilities are major part to maintain in hierarchal order, so that each and every level of individuals should ensure their roles and responsibilities. The modern framework have been introduced for individual levels (cure and care provider, entire healthcare organizer, healthcare planning \& control management) to maintain hierarchal level, which ensure responsibilities of all managerial areas [10]. Simulation models of operational research model for the decision and policy maker, clinicians, and health management of healthcare system have been produced to improve the work efficiency [11]. The team work capabilities that support collaborative distributed work to get powerful impact and effectiveness in healthcare service management, which improves healthcare system [12]. The impact of technology and effective collaboration work achievements of patient care, mobile devices designed and implemented for effective healthcare team functionality to develop the healthcare systems [13]. The health information technology (HIT) tradeoffs model in design and evaluation has been introduced to develop seven tradeoff patterns to understand HIT mediated changes [14]. The concept of effective care, cost optimization, effective team works, effective communications, comprehensive decision making, safety awareness, and its performance build effective clinical team of healthcare and social care environment [15]. We can summarize the existing concept of optimality, but cost optimization concept have not yet introduced in any research paper of healthcare. This paper addresses cost optimization methodology to develop an overall system of the healthcare. We are the first to propose a best cost optimization concept in healthcare. 


\section{Background Study of Brain-Tumor}

A brain is a complex and vital organ that makes up the central nervous system (CNS), where all vital functions are controlled. When tumor grows in the CNS, it affects a person's through processes, the way they talk, or movement. This disease is a particular abnormal condition that negatively affects the structure of function of part or all of an organ, and that is not due to an external injury. This disease affects the people at different levels, like physically, emotionally, socially, and financially. The introduced methodology makes aware of structure and functionality of brain, symptoms of brain tumor, initial level of test, grade of tumor, risk and possible side effects of treatment, treatment, and its cost. It is important to have an open and honest conversation of their issues with healthcare team and doctors to express their feelings and preferences. The healthcare team members and doctors have special skills, knowledge and experience to support patients and their families.

\subsection{Structure and functionality of brain}

Structure: The brain is made up of three main parts (The cerebrum, the cerebellum and the brain stem), these are the membranes, which surround and protect the brain and spinal cord. The cerebrum covers a largest part of brain which divided into the frontal lobe, Parietal lobe, Occipital lobe, and Temporal lobe. The cerebellum covers the back part of brain, just below the cerebrum. The Brain stem is a major part of brain, which is divided into Pons, and Medulla oblongata.

Functionality: The cerebrum contains two cerebral hemisphere on either side of the brain that control opposite sides of body. The cerebellum controls the same side of body. The brain stem conveys the messages for functions that are controlled by cerebrum and cerebellum travel the brain stem to the body, which controls the beating of the heart and breathing.

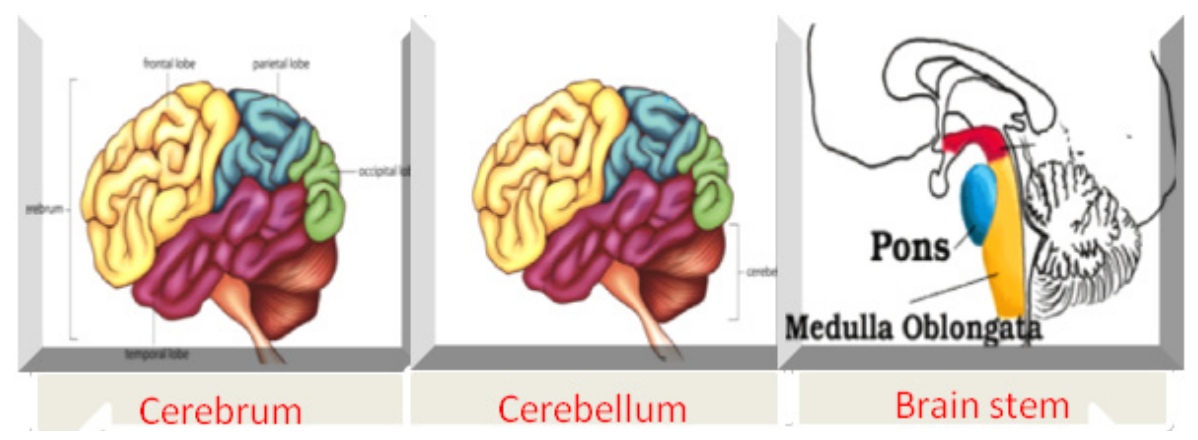

Fig. 1. Structure and Functionality of Brain 


\subsection{Brain-tumor sign and symptoms}

Something that can signal a problem, which are the symptoms or sign, may need medical care. If some parts or specific parts of brain are not working well or feeling headache or other changes, means changes may or may not cause a brain tumor. It is important for everyone to know the symptoms which concerned about any changes we experience, which help to get correct diagnosis and treatment. Determining the cause of symptoms is the first step towards getting the treatment. It needs the consultation of doctors who will figure out the cause of problems and will suggest the diagnosis for treatment accordingly. The sign and symptoms are listed in figure 2.

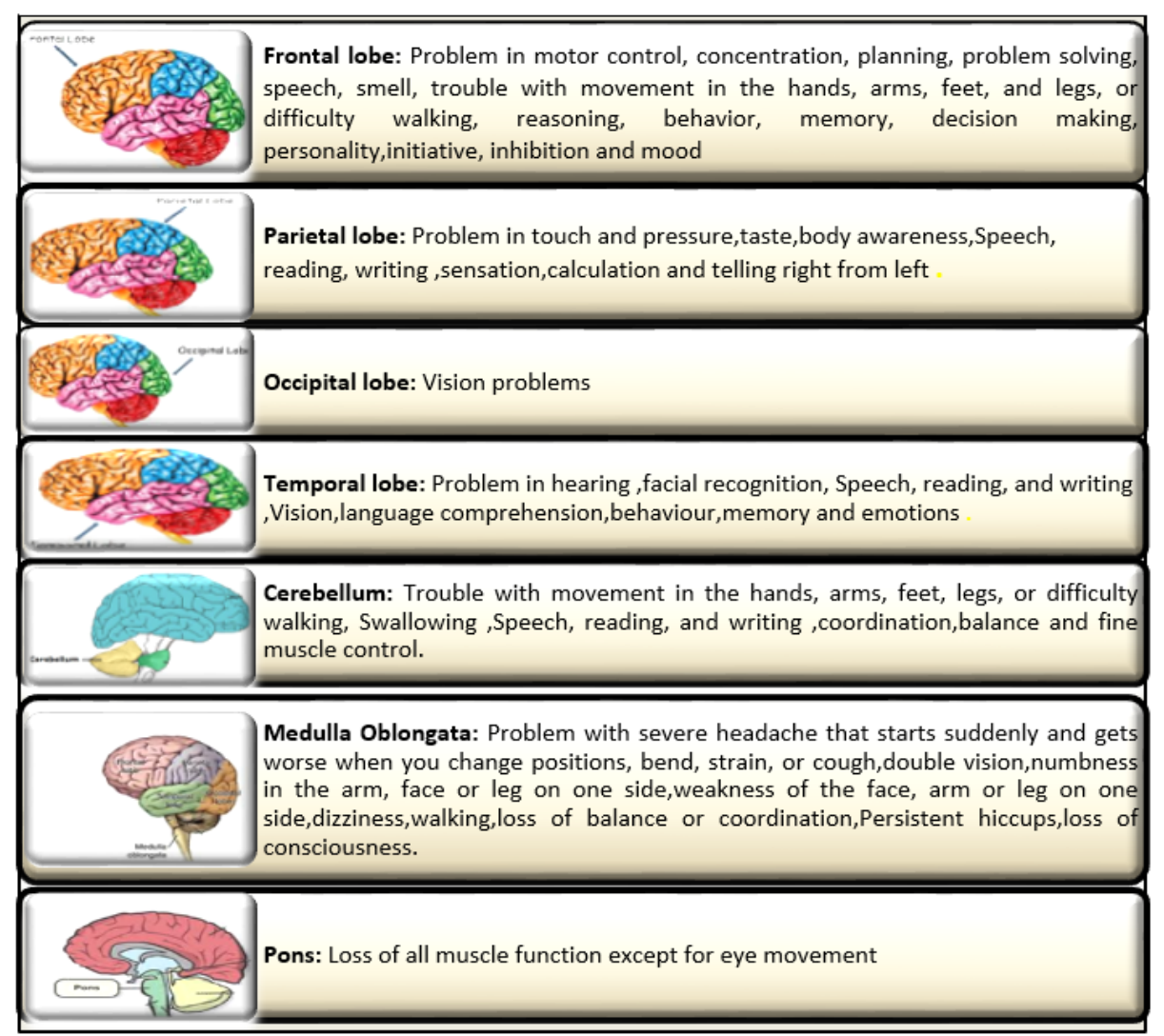

Fig. 2. Structures and Functionality of Brain 
Table 1. Initial level of test

\begin{tabular}{|l|l|}
\hline \multicolumn{1}{|c|}{ Test Name } & \multicolumn{1}{c|}{ Test Description } \\
\hline Intravenous(IV) gadolinium-enhanced MRI & It gives clear picture of brain tumor. \\
\hline Spinal MRI & Diagnose a tumor on or near the spin. \\
\hline A functional MRI (fMRI) & $\begin{array}{l}\text { Information of specific area of brain, which are responsible } \\
\text { for muscle movement and speech }\end{array}$ \\
\hline MRS using MRI & $\begin{array}{l}\text { Magnetic resonance spectroscopy (MRS) provides an } \\
\text { information on the chemical composition of the brain. }\end{array}$ \\
\hline CT Scan & $\begin{array}{l}\text { It helps to find bleeding and enlargement of the fluid-filled } \\
\text { spaces in the brain, called ventricles. }\end{array}$ \\
\hline PET-CT Scan & $\begin{array}{l}\text { It helps to find out more about tumor while a patient is } \\
\text { receiving treatment. }\end{array}$ \\
\hline Molecular testing of tumor & $\begin{array}{l}\text { It helps to identify specific genes, proteins, and other factors, } \\
\text { such as tumor marker, unique to the tumor. }\end{array}$ \\
\hline Neurological test & It helps to detect the brain functionality. \\
\hline Vision and hearing test & $\begin{array}{l}\text { It helps to detect the changes in the optic nerve and field of } \\
\text { vision. }\end{array}$ \\
\hline Neurocognitive assessment & It helps to detect the functionality of brain. \\
\hline Electroencephalography(EEG) & It helps to measure the electrical activity of brain. \\
\hline Evoked potentials & It helps to measure the electrical activity of nerves. \\
\hline Cerebral angiogram & It helps to find the arteries in the brain. \\
\hline Lumber puncture or spinal tap & It helps to find tumor cells. \\
\hline Myelogram & $\begin{array}{l}\text { It helps to find out the tumor status in spinal fluid, spinal cord } \\
\text { or other parts of brain. }\end{array}$ \\
\hline
\end{tabular}

Initial level of test: The data have been considered from some of reputed Indian diagnosis center. Dr. Pervez Ahmed Khan is a Consultant - Neurosurgery at Batra Hospital, New Delhi has provided data's of diagnosis and its respective details for the set of diagnosis from supply point $\mathrm{i}$ to demand point $\mathrm{j}$. Diagnosis which result for similar symptom have been grouped together as $\mathrm{Gj}$ with per unit cost, for all $\mathrm{j}$. We have proposed a methodology of optimality to optimize the cost of brain tumor treatment. The expertise of medical science people like, doctor, and health care team may use our proposed approach to get an optimal solution.

In table 1 , the different diagnoses are described, and in figure 3 , diagnoses have been categorized as a group with the similar result and it is per unit cost.

Brain-tumor grades: In general, diagnosis of brain tumor starts with magnetic resonance imaging (MRI). This diagnosis is used to measure the tumor's size. While receiving a treatment, patient need a regular monitor of health through brain MRI at every 2 to 3 months, as depends on tumor grade, MRI scans time length get increased. It gives detailed pictures than $\mathrm{CT}$ scans and preferred to diagnose a brain tumor. During treatment, if tumor get grows, other option will be considered for the treatment. As symptoms are explained, MRI may be of brain, spinal cord, or for both, depends on tumor suspected and determine which types of MRI required. It also depends on the result of neuro-examination, done by internist or neurologist. To detect, where is the tumor located? A staging system is used to describe it. There are several factors, which help doctor to find the tumor cell, whether it is growing out of control or a lot of dead cells that help him for appropriate brain tumor treatment plan 
and determine prognosis. Based on different grades of tumor, doctors suggest different types of treatment.

Table 2. Grades of Brain-tumor

\begin{tabular}{|c|l|}
\hline Grades & \multicolumn{1}{|c|}{ Status of tumor and its treatment } \\
\hline I & Slow growing and unlike to spread. It can cured by surgery \\
\hline II & Less likely to grow, it can cured after treatment \\
\hline III & Rapidly dividing cells but no dead cells, the can grow quickly, need immediate treatment \\
\hline IV & Blood vessels growth and areas of dead tissue, tumor can grow and spread quickly \\
\hline
\end{tabular}

\section{Risk factors of developing brain-tumor}

- People of any age can develop a brain tumor, but as per doctors' report, it is common in children and older adults.

- The ratio of brain tumor in men and women: men are more likely than women but are specific types of this disease are more common in women which is meningioma.

- One of the factor is hereditary genetic and its chances are up to $5 \%$.

- Exposure to infections, viruses, and allergens increase the risk of CNS lymphoma.

- Electromagnetic fields, which are energy from power line or from cell phone use. World Health Organization (WHO) recommends limiting cell phone use and promotes the use of a hands-free headset for both adults and children.

- Ionizing radiations including x-rays, have been shown to be a risk factor for brain tumor.

- Head injury and seizures have long been associated with brain tumors, which increase the risk.

- n-Nitroso compounds: There are certain reasons of this disease, which are cigarettes smoke, cured meats and cosmetics.

Treatment and its cost: For standard care, all the treatment options get considered, which helps doctors to find the better treatment. Different specialist work together in a multidisciplinary team, which helps them to find overall treatment of patient that combines different levels of treatment.

Table 3. Symptoms and treatment

\begin{tabular}{|l|l|}
\hline \multicolumn{1}{|c|}{ Symptoms } & \multicolumn{1}{c|}{ Treatment } \\
\hline The size, type, and grade of tumor & Surgery (for low grade tumor) \\
\hline Status of tumor on vital parts of brain & Surgery and Radiation therapy \\
\hline Spread ratio of tumor in other parts of body & Surgery, Radiation therapy, and chemotherapy \\
\hline Possible side effects & Radiation therapy can damage healthy tissue \\
\hline Patients overall health & Treatment often cause side effects \\
\hline
\end{tabular}


Paper-A New Neuroinformatics Approach to Optimize Diagnosis Cost in Neurology...

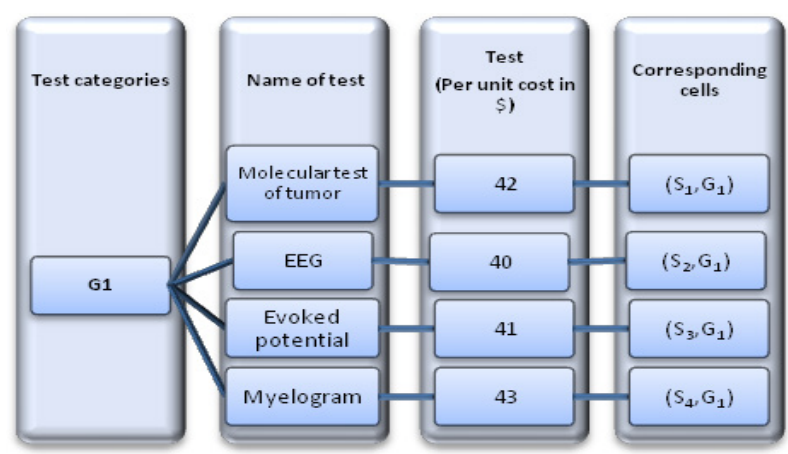

(a)

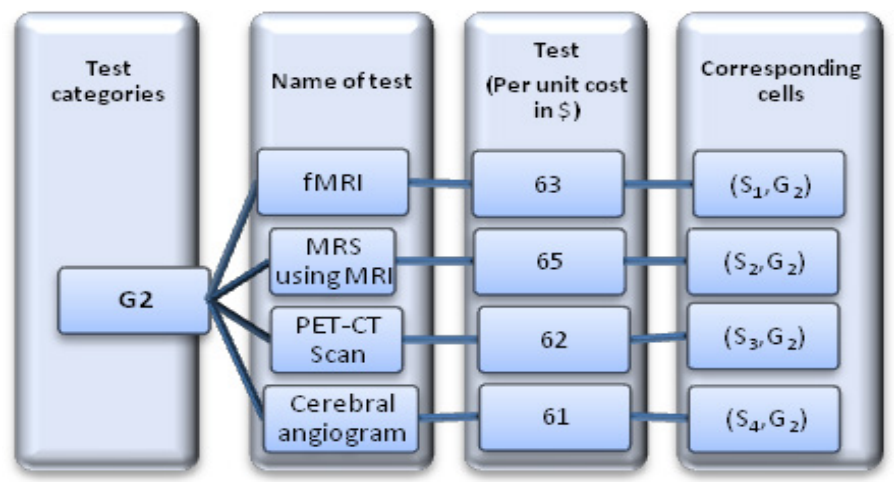

(b)

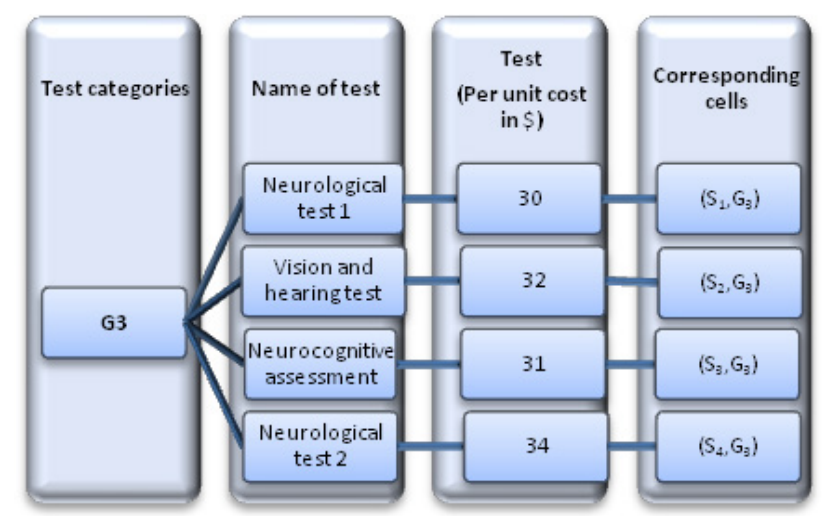

(c) 


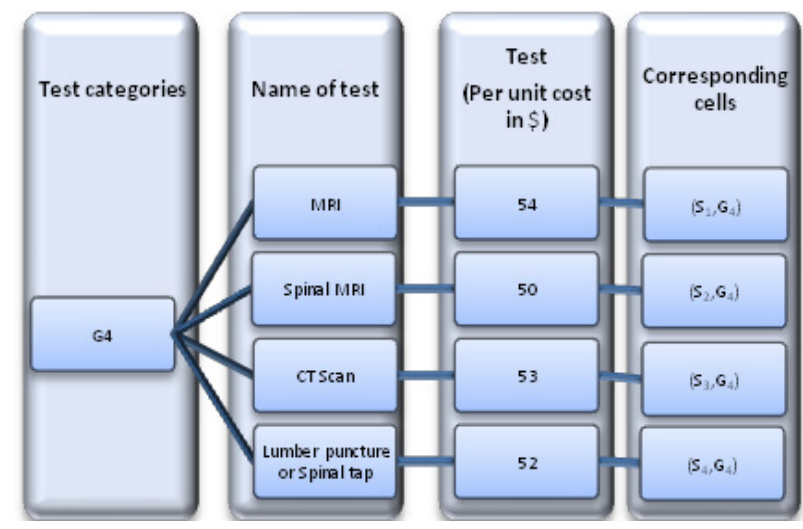

(d)

Fig. 3. Per unit cost of similar types of diagnosis: (a),(b),(c), and (d) are different groups of similar types of diagnosis with per unit cost

\section{Data Description}

In our approach, all the information and data have been collected from different medical research centre and cancer hospital. RGCIRC is a project of Indraprastha Cancer Society and Research Centre, a not-for-profit public society. It is one of the largest medical centers for cancer treatment in Asia. Dr. Pervez Ahmed Khan is a Consultant - Neurosurgery at Batra Hospital, New Delhi. Once, I discussed with Dr. Perwez regarding mathematical approach of cost optimization of brain tumor treatment. He accepted my proposal and provided valuable information and data of diagnosis and its respective details for the set of diagnosis to implement my approach. Diagnosis which result for similar symptom have been grouped together as $\mathrm{Gj}$ with per unit cost, for all $\mathrm{j}$. We have proposed a methodology of optimality to optimize the cost of brain tumor treatment. The expertise of medical science people like, doctor, and health care team may use my proposed approach to get an optimal solution. In table 1, the different diagnoses are described, and in figure 3, diagnoses have been categorized as a group with the similar result and it's per unit cost.

\section{Methods}

If the objective function is $f(X)$ and $X \in S$, where $s$ is the set of all feasible values of $X$. then $X^{*} \in S$ and $f^{*}(X) \leq f(X)$ for all $X \in S$, where $X^{*}$ is a minimizer of "f" on $S$.

The concepts of Linear programming (LP) have been implemented to find the least expensive way to meet the requirements. To minimize the cost of different set of diagnosis ( $\mathrm{S} 1$ to $\mathrm{Si}$ ) and their group categories which result a similar symptoms (G1 to $\mathrm{Gj}$ ), where $i$ and $j$ are the number of set of diagnosis and the number of group categories. Per unit cost of diagnosis are defined in a table i.e. Cij. Let us assume that 
the variables $\mathrm{Xi}$ are the non-negative variables denoting the number of diagnosis of different sets which are used to meet the requirement $j=1,2 \ldots n$. and $i=1,2 \ldots \mathrm{m}$ which are corresponding name of diagnosis and sets of diagnosis. One unit of test $\mathrm{j}$ contributes aij unit of set $\mathrm{i}$, where $\mathrm{Cj}$ is per unit cost of diagnosis $\mathrm{j}$. The objective is to determine the variable $\mathrm{Xj}$ to minimize the total cost of diagnosis.

4.1 Balanced Transportation Problem (BTP): Representation of supply demand diagnosis tableau

Table 4. Supply-Demand diagnosis tableau

\begin{tabular}{|c|c|c|c|c|c|}
\hline & $\mathbf{G}_{1}$ & $\mathbf{G}_{2}$ & $\ldots$ & $\mathbf{G}_{\mathbf{j}}$ & \\
\hline \multirow{2}{*}{$\mathrm{S}_{1}$} & $\mathrm{C}_{11}$ & $\mathrm{C}_{12}$ & $\ldots$ & $\mathrm{C}_{1 \mathrm{j}}$ & $\mathrm{a}_{1}$ \\
& $\mathrm{X}_{11}$ & $\mathrm{X}_{12}$ & & $\mathrm{X}_{1 \mathrm{j}}$ & \\
\hline \multirow{2}{*}{$\mathrm{S}_{2}$} & $\mathrm{C}_{21}$ & $\mathrm{C}_{22}$ & $\cdots$ & $\mathrm{C}_{2 \mathrm{j}}$ & $\mathrm{a}_{2}$ \\
\hline$\ldots$ & $\mathrm{X}_{21}$ & $\mathrm{X}_{22}$ & & $\mathrm{X}_{2 \mathrm{j}}$ & \\
\hline \multirow{2}{*}{$\mathrm{S}_{\mathrm{i}}$} & $\ldots$ & $\ldots$ & $\ldots$ & $\ldots$ & $\ldots$ \\
\hline & $\mathrm{C}_{\mathrm{i} 1}$ & $\mathrm{C}_{\mathrm{i} 2}$ & $\cdots$ & $\mathrm{C}_{\mathrm{ij}}$ & $\mathrm{a}_{\mathrm{i}}$ \\
\hline & $\mathrm{X}_{\mathrm{i} 1}$ & $\mathrm{X}_{\mathrm{i} 2}$ & & $\mathrm{X}_{\mathrm{ij}}$ & \\
\hline
\end{tabular}

$\left(S_{i}, G_{j}: C_{i j}\right) \rightarrow$ Set of supply and demand with per unit cost $X_{i j} \rightarrow$ Quantity transported from supply point $i$ to demand point $j$.

$$
\left.\begin{array}{rl}
S_{i} & \rightarrow\left(a_{i}\right)_{i \rightarrow 1} \text { to } m \\
\text { Supply } \rightarrow \text { Set } & \text { of diagnosis } \\
\left(S_{i}\right)_{i=1} & \rightarrow C_{1 j} \\
\left(S_{i}\right)_{i=2} & \rightarrow C_{2 j} \\
\cdot & \\
\cdot & \cdot \\
\left(S_{i}\right)_{i=m} & \rightarrow C_{i j} \\
G_{J} & \rightarrow\left(b_{j}\right)_{j \rightarrow 1 \text { to } n}
\end{array}\right\} j=1 \text { to } n
$$

Demand $\rightarrow$ Which result similar symptoms

$$
\begin{aligned}
\left(G_{J}\right)_{J=1} & \rightarrow C_{i 1} \\
\left(G_{j}\right)_{j=2} & \rightarrow C_{i 2} \\
\cdot & \cdot \\
\left(G_{j}\right)_{j=n} & \rightarrow C_{i j}
\end{aligned}
$$

$$
\operatorname{Minimize} \sum_{j=1}^{n} c_{j} x_{j}
$$




$$
\begin{gathered}
\text { Subject to } \sum_{j=1}^{n} a_{i j} x_{j} \geq \mathrm{b}_{j}, \text { for all } \mathrm{j} \\
x_{j} \geq 0 \text {, for all } \mathrm{j}
\end{gathered}
$$

To enhance the probability, constraints might be used, in which the model can be modified as lower and upper bonds on the amount of individual diagnosis in the treatments.

\section{Random test: Worst case}

Random test-1 (RT-1)

$$
\begin{aligned}
& \operatorname{Minimize} \sum_{j=1}^{n} C_{j} X_{j}
\end{aligned}
$$

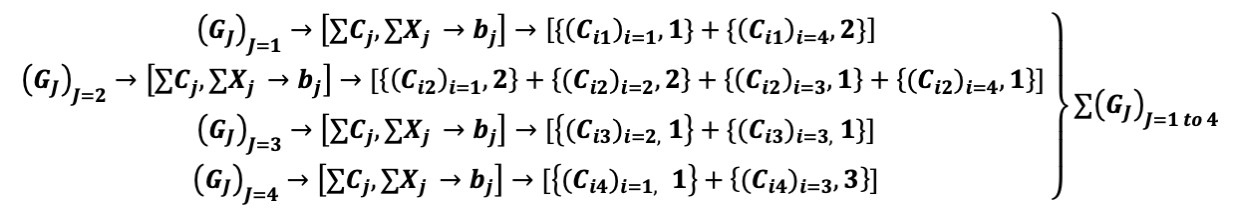$$
=\$ 826
$$

Random test-2 (RT-2)

$$
\left.\begin{array}{c}
\text { Minimize } \sum_{j=1}^{n} C_{j} X_{j} \\
\left(G_{J}\right)_{J=1} \rightarrow\left[\sum C_{j}, \sum X_{j} \rightarrow b_{j}\right] \rightarrow\left[\left\{\left(C_{i 1}\right)_{i=3}, 2\right\}+\left\{\left(C_{i 1}\right)_{i=4}, 1\right\}\right] \\
\left(G_{J}\right)_{J=2} \rightarrow\left[\sum C_{j}, \sum X_{j} \rightarrow b_{j}\right] \rightarrow\left[\left\{\left(C_{i 2}\right)_{i=1}, 3\right\}+\left\{\left(C_{i 2}\right)_{i=2}, 2\right\}+\left\{\left(C_{i 2}\right)_{i=4}, 1\right\}\right] \\
\left(G_{J}\right)_{J=3} \rightarrow\left[\sum C_{j}, \sum X_{j} \rightarrow b_{j}\right] \rightarrow\left[\left\{\left(C_{i 3}\right)_{i=3,}, 1\right\}+\left\{\left(C_{i 3}\right)_{i=4}, 1\right\}\right] \\
\left(G_{J}\right)_{J=4} \rightarrow\left[\sum C_{j}, \sum X_{j} \rightarrow b_{j}\right] \rightarrow\left[\left\{\left(C_{i 4}\right)_{i=1}, 1\right\}+\left\{\left(C_{i 4}\right)_{i=2}, 1\right\}+\left\{\left(C_{i 4}\right)_{i=3}, 2\right\}\right]
\end{array}\right\} \sum\left(G_{J}\right)_{J=1 t o 4}
$$

Random test-3 (RT-3)

$$
\operatorname{Minimize} \sum_{j=1}^{n} C_{j} X_{j}
$$




$$
\left.\begin{array}{rl}
\left(G_{J}\right)_{J=1} & \rightarrow\left[\Sigma C_{j}, \Sigma X_{j} \rightarrow b_{j}\right] \rightarrow\left[\left\{\left(C_{i 1}\right)_{i=3}, 3\right\}\right] \\
\left(G_{J}\right)_{J=2} \rightarrow\left[\sum C_{j}, \Sigma X_{j} \rightarrow b_{j}\right] \rightarrow\left[\left\{\left(C_{i 2}\right)_{i=2}, 3\right\}+\left\{\left(C_{i 2}\right)_{i=4}, 3\right\}\right] \\
\left(G_{J}\right)_{J=3} & \rightarrow\left[\Sigma C_{j}, \Sigma X_{j} \rightarrow b_{j}\right] \rightarrow\left[\left\{\left(C_{i 3}\right)_{i=3}, 2\right\}\right] \\
\left(G_{J}\right)_{J=4} & \rightarrow\left[\Sigma C_{j}, \sum X_{j} \rightarrow b_{j}\right] \rightarrow\left[\left\{\left(C_{i 4}\right)_{i=1}, 4\right\}\right] \\
& =\$ 788
\end{array}\right\} \sum\left(G_{J}\right)_{J=1 t o 4}
$$

\subsection{Solution stages}

The solution to a TP has two stages; first stage to identify IBFS, and the second to get the optimal solution (OS). There are three standard methods of identifying IBFS (North-west corner cell method (NCCM), Minimum cost cell method (MCCM), and Vogel's approximation method (VAM)). We can choose either of these methods, out of which we are considering North-west corner cell method to find the IBFS and two standard methods of getting optimal solution (Stepping stone method, and Modified distribution method (MODI)/U-V Method). After getting the IBFS, we may apply either Stepping stone method or Modified distribution method to find out the optimal solution. Here, we have applied stepping stone method to find the optimal solution. User of our methodology (either doctor or healthcare team who have expertise in medical science) may provide better treatment in minimum cost. As per the symptoms of the disease in patients, user prescribe some diagnosis to identify the actual disease, which help him to provide better treatment. Our proposed methodology will help the patients to get their diagnosis in optimal cost.

As per the requirement of number of diagnosis, User may ask random number of different set of supply (a1 to a4), but supply should not get exceed or reduced the demand. Our proposed methodology may work for balanced transportation problem in which, total number of supplies are equal to total number of demand.

It is Microsoft Excel based application, which need to fill the required data in proposed transportation tableau to get the feasible and optimal result. The user need to fill per unit cost of different diagnosis in proposed transportation tableau with their similar property in given set of groups(G1, G2 ,.., Gj), and put the demand from the diagnosis center to fulfil the requirements of diagnosis, which makes the supply and demand in balanced.

$$
\begin{aligned}
& S_{i}:\left(a_{i}\right)_{i \rightarrow 1 \text { to } 4} \rightarrow(3,6,2,4) \\
& G_{J}:\left(b_{j}\right)_{j \rightarrow 1 \text { to } 4} \rightarrow(6,6,2,4)
\end{aligned}
$$

$$
\left.\begin{array}{c}
\text { Demand } \rightarrow \text { Which result similar symptoms } \\
\left(G_{J}\right)_{J=1} \rightarrow\left(C_{i 1}\right)_{i=1},\left(C_{i 1}\right)_{i=2},\left(C_{i 1}\right)_{i=3},\left(C_{i 1}\right)_{i=4} ;(\$ 42, \$ 40, \$ 41, \$ 43) \\
\left(G_{J}\right)_{J=2} \rightarrow\left(C_{i 2}\right)_{i=1},\left(C_{i 2}\right)_{i=2},\left(C_{i 2}\right)_{i=3,},\left(C_{i 2}\right)_{i=4} ;(\$ 63, \$ 65, \$ 62, \$ 61) \\
\left(G_{J}\right)_{J=3} \rightarrow\left(C_{i 3}\right)_{i=1},\left(C_{i 3}\right)_{i=2},\left(C_{i 3}\right)_{i=3,}\left(C_{i 3}\right)_{i=4} ;(\$ 30, \$ 32, \$ 31, \$ 34) \\
\left(G_{J}\right)_{J=4} \rightarrow\left(C_{i 4}\right)_{i=1},\left(C_{i 4}\right)_{i=2},\left(C_{i 4}\right)_{i=3,},\left(C_{i 4}\right)_{i=4} ;(\$ 54, \$ 50, \$ 53, \$ 52)
\end{array}\right\} i \text { to } 4
$$


Stage 1: To identify Initial Basic Feasible Solution (IBFS): Average Case: The TP talks about the diagnosis, a diagnosis from a given set of requirements. The given set of diagnosis $\mathrm{i}$ as ai and the requirement in diagnosis $\mathrm{j}$ is bj and the problem is one of finding a least cost treatment from the sets to the required diagnosis, where $\mathrm{Cij}$ is the per unit cost of diagnosis.

The problem is finalized as $\mathrm{Xij}$, the quantity of diagnosis given from sets $\mathrm{i}$ to required diagnosis $\mathrm{j}$. The objective function is to minimize the total cost of treatment CijXij subject to sets constraints.

For every set, ai is the quantity available in sets $\mathrm{i}$ and as far as every requirement parts are concerned.

$\sum \mathrm{ai}=$ Total availability, and $\sum \mathrm{bj}=$ Total requirements.

If $\sum \mathrm{ai} \geq \sum \mathrm{bj}$ and $\mathrm{Cij} \geq 0$ : Total availability is more than the requirements (possible to fulfill all requirements of different set of diagnosis)

If $\sum$ ai $<\sum b j$ and $C \mathrm{ij} \geq 0$ : Total availability is less than the requirements (then obviously all the requirements cannot be met).

\section{North-West Corner Cell Method (NCCM):}

Step 1: Begin in the upper left corner of the transportation table.

Step 2: Set X11, X11=min $\{\mathrm{a} 1, \mathrm{~b} 1\}$.

Step 3: if $X 11=a 1$, cross out row 1 , no more basic variables will come from row 1 and set $\mathrm{b} 1=\mathrm{b} 1-\mathrm{a} 1$.

Step 4: if $\mathrm{X} 11=\mathrm{b} 1$, cross out the column 1, no more basic variables will come from column 1 and set al=a1-b1.

Step 5: if $X 11=a 1-b 1$, cross out either row 1 or column 1 , but not both. Set $b 1=0$, when cross out row 1 . Otherwise set $\mathrm{a} 1=0$, when cross out column 1 .

Step 6: Continue to apply this procedure to the most north-west corner cell in the table that does not lie in a crossed-out row or column. Finally there will be only one cell that can be assigned a value (Assign this cell a value equal to its row or column demand, and cross out both the cells row and column).

Step 7: Now, IBFS has been obtained

$$
\operatorname{Minimize} \sum_{j=1}^{n} C_{j} X_{j}
$$

\section{Minimum Cost Cell Method (MCCM):}

Step 1: Find cell with smallest $\{\mathrm{Cij}\}$.

Step 2: Set Xij, Xij=min $\{a i, b j\}$ to cell of step 1 .

If $\mathrm{Xij}=\mathrm{ai}$, cross out row $\mathrm{i}$, no more basic variables will come from row $\mathrm{i}$ and set $\mathrm{bj}=\mathrm{bj}$-ai.

If $\mathrm{Xij}=\mathrm{bj}$, cross out the column $\mathrm{j}$, no more basic variables will come from column $\mathrm{j}$ and set $a i=a i-b j$.

If $\mathrm{Xij}=\mathrm{ai}-\mathrm{bj}=0$, cross out either row $\mathrm{i}$ or column $\mathrm{j}$, but not both. Set $\mathrm{bj}=0$, when cross out row $i$. Otherwise set $a i=0$, when cross out column $j$. 
Step 3: Continue to apply step 1 and step 2 with rest of the per unit cost element of transportation cost matrix. Finally there will be only one cell that can be assigned a value (Assign this cell a value equal to its row or column demand, and cross out both the cells row and column).

$$
\left.\begin{array}{c}
\text { Minimize } \sum_{j=1}^{n} C_{j} X_{j} \\
\left(G_{J}\right)_{J=1} \rightarrow\left[\sum C_{j}, \sum X_{j} \rightarrow b_{j}\right] \rightarrow\left[\left(C_{i 1}\right)_{i=2}, 3\right] \\
\left(G_{J=2} \rightarrow\left[\sum C_{j}, \sum X_{j} \rightarrow b_{j}\right] \rightarrow\left[\left\{\left(C_{i 2}\right)_{i=1}, 2\right\}+\left\{\left(C_{i 2}\right)_{i=3}, 4\right\}\right]\right. \\
\left(G_{J}\right)_{J=3} \rightarrow\left[\sum C_{j}, \sum X_{j} \rightarrow b_{j}\right] \rightarrow\left[\left(C_{i 3}\right)_{i=3}, 2\right] \\
\left(G_{J}\right)_{J=4} \rightarrow\left[\sum C_{j}, \sum X_{j} \rightarrow b_{j}\right] \rightarrow\left[\left\{\left(C_{i 4}\right)_{i=3}, 1\right\}+\left\{\left(C_{i 4}\right)_{i=4}, 3\right\}\right]
\end{array}\right\} \sum\left(G_{J}\right)_{J=1 t o 4}
$$

\section{Vogel's Approximation Method (VAM):}

Step 1. Find penalty by subtracting smallest per unit cost from next to smallest per unit cost in same row or column.

Allocate the variable to least possible per unit cost of largest penalty row or column, if penalty are ties then select arbitrarily. Adjust supply or demand as following: Step 2.

Set $\mathrm{X}_{\mathrm{ij}}=\min \left\{\mathrm{a}_{\mathrm{i}}, \mathrm{b}_{\mathrm{j}}\right\}$.

If $\mathrm{X}_{\mathrm{ij}}=\mathrm{a}_{\mathrm{i}}$, cross out row $\mathrm{i}$, no more basic variables will come from row $\mathrm{i}$ and set $\mathrm{b}_{\mathrm{j}}=\mathrm{b}_{\mathrm{j}}-\mathrm{a}_{\mathrm{i}}$.

If $\mathrm{X}_{\mathrm{ij}}=\mathrm{b}_{\mathrm{j}}$, cross out the column $\mathrm{j}$, no more basic variables will come from column $\mathrm{j}$ and set $a_{i}=a_{i}-b_{j}$.

If $X_{i j}=a_{i}-b_{j}=0$, cross out either row $i$ or column $j$, but not both. Set $b_{j}=0$, when cross out row $i$. Otherwise set $a_{i}=0$, when cross out column $j$.

Step3: Continue to apply this procedure. Finally there will be only one cell that can be assigned a value (Assign this cell a value equal to its row or column demand, and cross out both the cells row and column).

$$
\operatorname{Minimize} \sum_{j=1}^{n} C_{j} X_{j}
$$

$$
\left.\begin{array}{c}
\left(G_{J}\right)_{J=1} \rightarrow\left[\sum C_{j}, \sum X_{j} \rightarrow b_{j}\right] \rightarrow\left[\left\{\left(C_{i 1}\right)_{i=1}, 2\right\}+\left\{\left(C_{i 1}\right)_{i=3}, 1\right\}\right] \\
\left(G_{J}\right)_{J=2} \rightarrow\left[\sum C_{j}, \sum X_{j} \rightarrow b_{j}\right] \rightarrow\left[\left\{\left(C_{i 2}\right)_{i=3}, 4\right\}+\left\{\left(C_{i 2}\right)_{i=4}, 2\right\}\right] \\
\left(G_{J}\right)_{J=3} \rightarrow\left[\sum C_{j}, \sum X_{j} \rightarrow b_{j}\right] \rightarrow\left[\left(C_{i 3}\right)_{i=1}, 2\right] \\
\left(G_{J}\right)_{J=4} \rightarrow\left[\sum C_{j}, \sum X_{j} \rightarrow b_{j}\right] \rightarrow\left[\left\{\left(C_{i 4}\right)_{i=2,}\right\}+\left\{\left(C_{i 4}\right)_{i=4}, 1\right\}\right]
\end{array}\right\} \sum\left(G_{J}\right)_{J=1 t o 4}
$$




\section{Stage 2: To identify Optimal Solution (OS): Best Case}

Stepping stone method - to get the optimal solution $(O S)$ : The steps are involved to check the optimality of the initial basic feasible solution using the stepping stone method:

Step 1:Condition to solve for the optimality is to ensure that the number of allocated cells is exactly equal to $m+n-1$, where ' $m$ ' is the number of rows, while ' $n$ ' is equal to the number of columns, if this condition fail, means the allocated cells are less than $\mathrm{m}+\mathrm{n}-1$ (degenerate feasible solution exist).

Step 2: When degenerate feasible solution exist, consider $\varepsilon$ to make the condition BFS, choose the position in which it should retain the fact that these $m+n-1$ positions are independent and assume $\varepsilon=0$ as an allocation.

Step 3: Select unallocated cell, move with allocated cell, either horizontally or vertically and returns to the same unallocated cell, called as a "closed loop". Such that, no three consecutive allocated cells either be in the same row or column.

Step 4: Once the loop is created, assign "+" or "-_sign alternatively on each corner cell of the loop, but begin with the "+" sign for the unallocated cell.

Step 5: Repeat these steps again until all the unallocated cells get evaluated. If all the computed changes are $\geq 0$, then the optimal solution has been reached.

Step 6: But in case, if any value comes to be negative, then there is a scope to reduce the transportation cost further. Then, select that unallocated cell which has the most negative change and assign as many units as possible. Subtract the unit that added to the unallocated cell from the other cells with a negative sign in a loop, to balance the demand and supply requirements.

Net cost (Increased/Decreased): In table 5, Applying step1 to step5 of stepping stone method to check the computed changes are either $<$ or $\geq 0$, if all computed changes are $\geq 0$, then the optimal solution has been reached, but the net cost have decreased, next step(step 6) is require to check the optimality condition. When net cost increased, means optimality condition reached.

The Stepping stone method, to check the net cost by putting +1 one by one in per unit cost cell to all unallocated cell. Start from this unallocated cell with +1 and move to other allocated cell with alternate sign to form a loop. Continue this process one by one with all unallocated cell. The sign of the net cost will show that either net cost is increasing or decreasing.

Table 5. Initial transportation tableau of optimal solution

\begin{tabular}{|l|l|c|c|}
\hline Unallocated cell & Loop of per unit cost cell & Net cost $\uparrow$ & Net cost $\downarrow$ \\
\hline$X_{13}$ & $C_{13}-C_{33}+C_{32}-C_{12}$ & - & 4 \\
\hline$X_{14}$ & $C_{14}-C_{34}+C_{32}-C_{12}$ & 0 & 0 \\
\hline$X_{21}$ & $C_{21}-C_{22}+C_{12}-C_{11}$ & - & 4 \\
\hline$X_{23}$ & $C_{23}-C_{33}+C_{32}-C_{22}$ & 4 & - \\
\hline$X_{24}$ & $C_{24}-C_{34}+C_{32}-C_{22}$ & - & 6 \\
\hline$X_{31}$ & $C_{31}-C_{32}+C_{12}-C_{11}$ & 0 & 0 \\
\hline$X_{41}$ & $C_{41}-C_{11}+C_{12}-C_{32}+C_{34}-C_{44}$ & 3 & - \\
\hline$X_{42}$ & $C_{42}-C_{32}+C_{34}-C_{44}$ & 3 & - \\
\hline$X_{43}$ & $C_{43}-C_{44}+C_{34}-C_{33}$ & 4 & - \\
\hline
\end{tabular}


In table 6, Applying Step 6 of stepping stone method, because net cost has decreased, then there is a scope to reduce the transportation cost further. Then, select that unallocated cell which has the most negative change and assign as many units as possible. Subtract the unit that added to the unallocated cell from the other cells with a negative sign in a loop, to balance the demand and supply requirements.

Table 6. After applying step 6 of stepping stone method

\begin{tabular}{|l|l|c|c|}
\hline Unallocated cell & \multicolumn{1}{|c|}{ Loop of per unit cost } & Net cost $\uparrow$ & Net cost $\downarrow$ \\
\hline $\mathrm{X}_{14}$ & $\mathrm{C}_{14}-\mathrm{C}_{11}+\mathrm{C}_{21}-\mathrm{C}_{24}$ & 2 & - \\
\hline $\mathrm{X}_{22}$ & $\mathrm{C}_{22}-\mathrm{C}_{21}+\mathrm{C}_{11}-\mathrm{C}_{12}$ & 4 & - \\
\hline $\mathrm{X}_{23}$ & $\mathrm{C}_{23}-\mathrm{C}_{21}+\mathrm{C}_{11}-\mathrm{C}_{13}$ & 2 & - \\
\hline $\mathrm{X}_{31}$ & $\mathrm{C}_{31}-\mathrm{C}_{32}+\mathrm{C}_{12}-\mathrm{C}_{11}$ & 0 & - \\
\hline $\mathrm{X}_{33}$ & $\mathrm{C}_{33}-\mathrm{C}_{13}+\mathrm{C}_{12}-\mathrm{C}_{32}$ & 2 & - \\
\hline $\mathrm{X}_{34}$ & $\mathrm{C}_{34}-\mathrm{C}_{24}+\mathrm{C}_{21}-\mathrm{C}_{11}+\mathrm{C}_{12}-\mathrm{C}_{32}$ & 2 & - \\
\hline $\mathrm{X}_{41}$ & $\mathrm{C}_{41}-\mathrm{C}_{44}+\mathrm{C}_{24}-\mathrm{C}_{21}$ & 1 & - \\
\hline $\mathrm{X}_{42}$ & $\mathrm{C}_{42}-\mathrm{C}_{44}+\mathrm{C}_{24}-\mathrm{C}_{21}+\mathrm{C}_{11}-\mathrm{C}_{12}$ & 1 & - \\
\hline $\mathrm{X}_{43}$ & $\mathrm{C}_{43}-\mathrm{C}_{44}+\mathrm{C}_{24}-\mathrm{C}_{21}+\mathrm{C}_{11}-\mathrm{C}_{13}$ & 4 & - \\
\hline
\end{tabular}

All the computed changes are $\geq 0$, and then the optimal solution has been reached.

Optimal solution $(\mathrm{OS})=($ Per unit cost of allocated cell)*(Quantity of allocated cell which are transported from supply point $\mathrm{i}$ to demand point $\mathrm{j}$ )

$$
\text { Minimize } \sum_{j=1}^{n} C_{j} X_{j}
$$

$$
\left.\begin{array}{c}
\left(G_{J}\right)_{J=1} \rightarrow\left[\sum C_{j}, \sum X_{j} \rightarrow b_{j}\right] \rightarrow\left[\left\{\left(C_{i 1}\right)_{i=1}, 1\right\}+\left\{\left(C_{i 1}\right)_{i=2}, 2\right\}\right] \\
\left(G_{J}\right)_{J=2} \rightarrow\left[\sum C_{j}, \sum X_{j} \rightarrow b_{j}\right] \rightarrow\left[\left\{\left(C_{i 2}\right)_{i=1}, 1\right\}+\left\{\left(C_{i 2}\right)_{i=3}, 5\right\}\right] \\
\left(G_{J}\right)_{J=3} \rightarrow\left[\sum C_{j}, \sum X_{j} \rightarrow b_{j}\right] \rightarrow\left[\left(C_{i 3}\right)_{i=1}, 2\right] \\
\left(G_{J}\right)_{J=4} \rightarrow\left[\sum C_{j}, \sum X_{j} \rightarrow b_{j}\right] \rightarrow\left[\left\{\left(C_{i 4}\right)_{i=2,}\right\}+\left\{\left(C_{i 4}\right)_{i=4}, 3\right\}\right]
\end{array}\right\} \sum\left(G_{J}\right)_{J=1 t o 4}
$$

\section{$5 \quad$ Experiment and Results}

\subsection{Experiment}

In this work, considering the number of supplied diagnosis from supply point $i$ and requirements of diagnosis at demand point $\mathrm{j}$. In order to obtain the optimal solution, a stepping stone method was applied to evaluate the performance of our proposed approach. Specifically, the input dataset was taken from some of Indian diagnosis center that have shown in figure 3. The cost of individual diagnosis have converted from Indian currency to dollar. Diagnosis which result for similar symptom have grouped together as $\mathrm{Gj}$ for all $\mathrm{j}$. Since we aimed to solve three different cases of problems, the measurement of optimality, stepping stone method was used to 
optimize the treatment cost of brain tumor patients. We also evaluated the different cases to compare the performance of our proposed approach.

Comparison between Allocated cells of supply- demand diagnosis tableau:

Worst, average and best cases

- Worst case: RT's (Random test-1, Random test-2, Random test-3)

- Average case : IBFS (NCCM, MCCM,VAM)

- Best case: OS (Stepping stone method (SSM), Modified distribution method (MODI)/U-V Method)

$$
\begin{aligned}
& C_{i j} X_{i j} \rightarrow \text { Set of constraints } \\
& \phi_{\boldsymbol{i} \boldsymbol{j}} \rightarrow \boldsymbol{S}_{\boldsymbol{i}} \boldsymbol{G}_{\boldsymbol{j}} \text { Cells for } \boldsymbol{i} \& \boldsymbol{j}
\end{aligned}
$$

The objective of our work is to minimize the total cost of treatment with $\mathrm{Xij} \rightarrow$ Quantity of diagnosis supplied from supply point I to demand point $\mathrm{j}$ with per unit cost $\mathrm{Cij}$

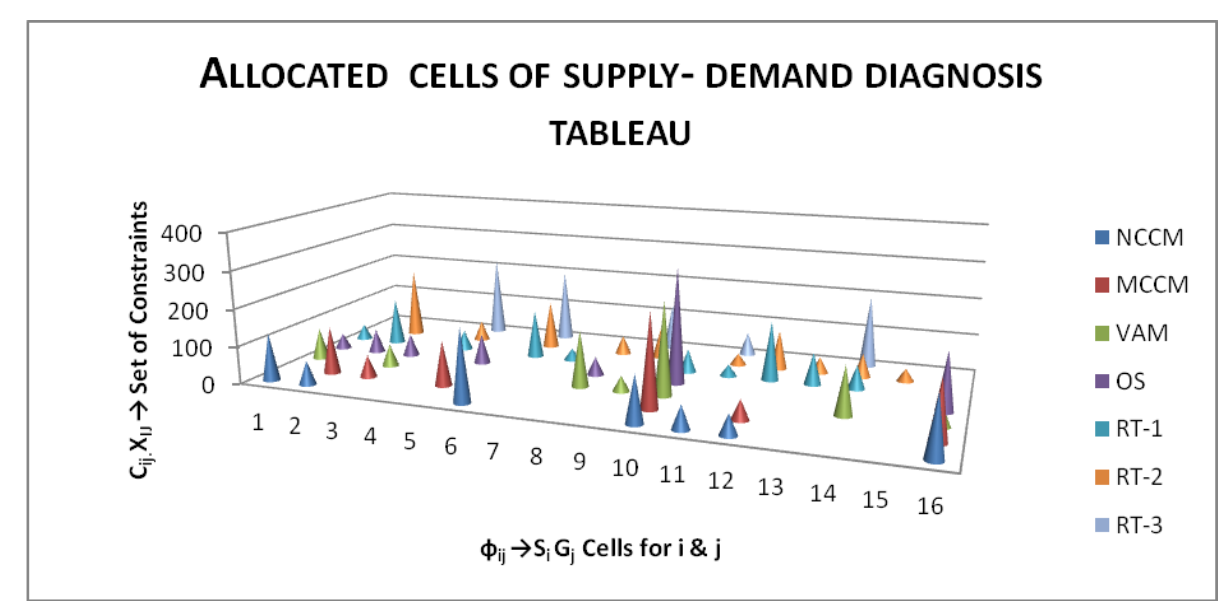

Fig. 4. The column plots of \# each cases sorted by Sets of allocated cells and its constraints

\subsection{Result}

\section{Cost comparison between worst, average and best cases}

- Worst case: RT's (Random test-1, Random test-2, Random test-3)

- Average case : IBFS (NCCM, MCCM,VAM)

- Best case: OS (Stepping stone method (SSM), Modified distribution method (MODI)/U-V Method) 
Table 7. Cost comparison between different processes

\begin{tabular}{|c|l|c|c|c|c|}
\hline Cases & Method & Total Cost (in \$) & Cost Diff. (with OS) & Extra cost in \$) & $\begin{array}{c}\text { Extra cost } \\
\text { (in \%) }\end{array}$ \\
\hline \multirow{2}{*}{$\begin{array}{c}\text { IBFS } \\
\text { (Avg. case) }\end{array}$} & MCCM & 763 & $763-761$ & 2 & 0.26 \\
\cline { 2 - 6 } & VAM & 763 & $763-761$ & 2 & 0.26 \\
\cline { 2 - 6 } & NCCM & 779 & $779-761$ & 18 & 2.31 \\
\hline OS (Best case) & SSM/MODI & 761 & $761-761$ & 0 & 0 \\
\hline \multirow{2}{*}{$\begin{array}{c}\text { RT } \\
\text { (Worst case) }\end{array}$} & RT-1 & 826 & $826-761$ & 65 & 7.87 \\
\cline { 2 - 6 } & RT-2 & 783 & $783-761$ & 22 & 2.81 \\
\cline { 2 - 6 } & RT-3 & 788 & $788-761$ & 27 & 3.43 \\
\hline
\end{tabular}

In the graphs (figures $5 \& 6$ ), it is simple to see the difference between three different process (IBFS, OS, and RT). The SSM/MODI method to optimize the cost of diagnosis. Left to optimal solution, IBFS exit, and right to optimal solution, RT's are exist. Sometimes, we may find the solution through the IBFS to minimize the cost of diagnosis, but the optimality is the best process to achieve optimal solution, which will reduce the cost of group of diagnosis with similar symptoms that help the patient to get the diagnosis in minimum cost. Figure 3 is the collection of required data, group of similar diagnosis, and per unit cost of different diagnosis, and the process, which are collecting number of diagnosis accordingly to result performs. Figure 3 is showing the cost of diagnosis of groups from supply point $i$ to demand point $j$.

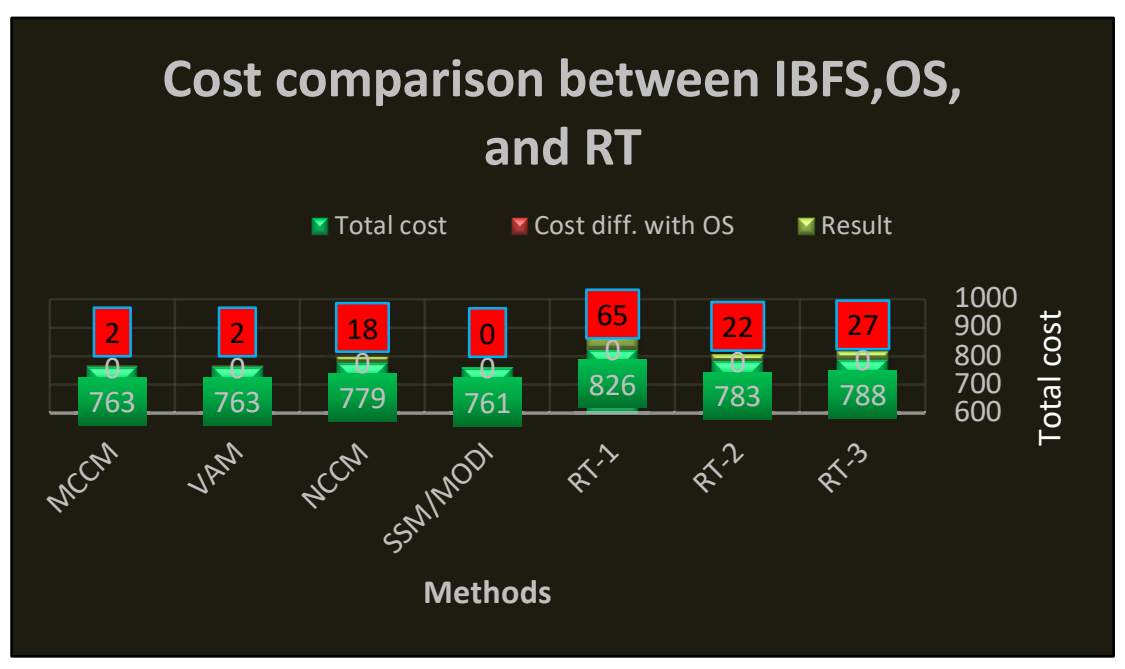

Fig. 5. Cost comparison between different process (in \$) 


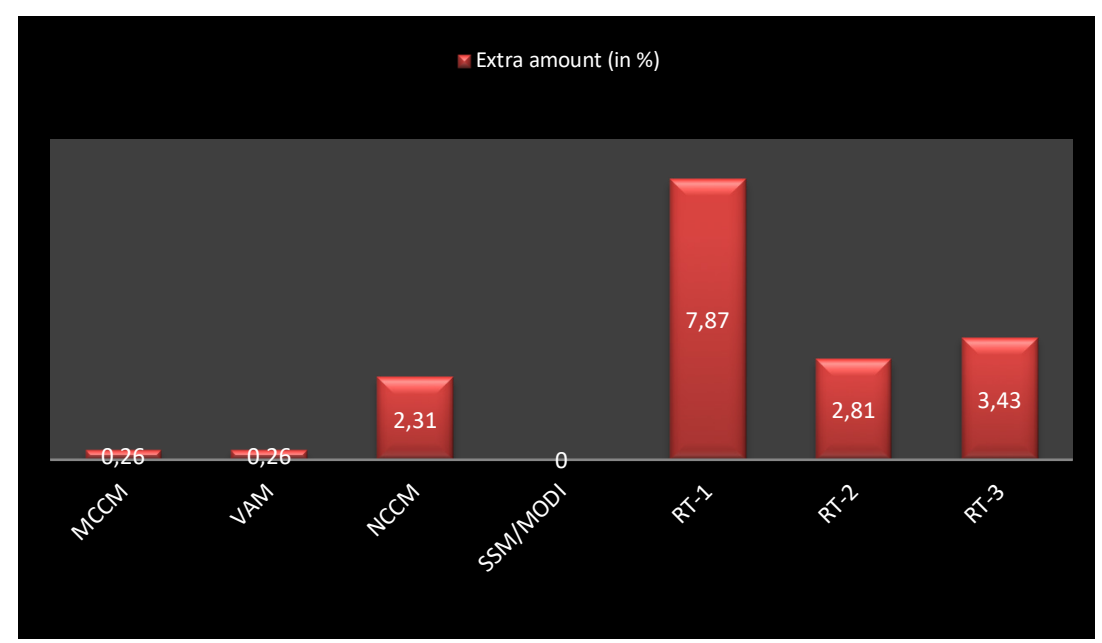

Fig. 6. Cost comparison between different process (in \%)

\section{Discussion}

In this study, we aimed to detect the optimal result by using stepping stone method of LPP. To our knowledge, this is the first approach to investigate the effective approach to minimize the diagnosis cost in healthcare. Using optimization approach of LPP, optimized solution were detected with excellent performance (all the casesbest, average, and worst cases) have been discussed. The performance of IBFS's are near about OS, but RT's are the worst case to implement for optimizing the result. Multiple sets of diagnosis are supplied from supply point $i$ to demand point $j$, out of which, the diagnosis that result similar symptoms are grouped. This is illustrated in figure 3 that compares all the cases of different methods. It can be clearly seen that our objective is meeting the requirements. The proposed methodology is cost effective. The treatment cost of brain-tumor is expensive. In addition to treatment cost, many people find unplanned extra expenses related to their care. For some people, the cost becomes reason for them to get their complete treatment. It can create an issue that make their health at risk and may lead to higher cost in future. A cost effective methodology have proposed for patients to get their treatment in optimal cost. The concept of optimality of OR has been implemented to optimize the cost of brain tumor treatment. The optimal solution is a set of optimization and feasible solution, which minimize the cost of treatment in healthcare. A set of choices that result in the condition being satisfied is called feasible solution. The objective of this paper is to give a methodology of optimality, which provides the optimal cost solution of brain tumor treatment. There are two steps to reach up to the optimal result. First step to get the feasible solution by applying either of these three standard methods (North-west corner cell method, Minimum cost cell method, or Vogel's approximation method) of transportation problem, then Stepping stone method or 
Modified distribution methods of OR are used to get the optimal solution, which resulted in minimum cost of brain tumor treatment.

\section{Conclusion}

The main objective of this paper is to provide a cost effective methodology that help the healthcare team and doctors to choose the selective diagnosis, which minimize the cost and side effects of treatment. The scientist and doctors are trying to get the better solution of the treatment of brain tumor in minimum cost with minimum side effects. Treatment of brain tumor is expensive. In addition to treatment cost, many people find unplanned extra expenses related to their care. For some people, the cost becomes reason for them to get their complete treatment. It can create an issue, which makes their health at risk and may lead to higher costs in future. Our proposed approach will help them to get their treatment in optimal cost. The optimization detection using stepping stone method achieved excellent performance for minimizing the treatment cost of brain tumor followed by IBFS's. We provide excellent approach for detecting OS. In future research, we recommend the following useful approach that should improve the concept in healthcare to minimize the cost of diagnosis as well as in different respect to optimize the difficulties and provide useful results towards development in healthcare.

\section{References}

[1] $\mathrm{K} . \mathrm{Xu}$ et al., "Tuberculosis in China: A longitudinal predective model of the general population and recommendations for achieving WHO goals", vol 22, no. 7, pp. 1423-1429, 2017

[2] N.Howleder et al., "SEER cancer statustics review. 1975-2014." Nat. cancer inst. Bethesda MD USA. Apr 2017, (online) Available: https:// seer.cancer.gov/csr/1975_2014/

[3] K. He et al., identity mappings in deep residual networks." In proc. Eur. Conf. comput. Vis 2016. Pp 630-645.

[4] Tao Tan, et al., "optimize transfer learning for lung deseases in Bronchoscopy using a new concept: sequential fine-tuning". IEEE journal of translational engineering in health and medicine, vol. 6,2018

[5] Alfonso R. Romero-Conradoa, Lauren J. Castro-Bolañoa, b, Jairo R. Montoya-Torres c \& Miguel Á. Jiménez-Barros. Operations research as a decision-making tool in the health sector: A state of the art. Romero-Conrado et al / DYNA 84(201), pp. 129-137, June, 2017

[6] Ehrgott M, Holder A. Operation research methods for optimization in radiation oncology. J Radiation Oncol informatics 2014;6:1-41

[7] Thomas SJ, Capacity and demand models for Radiotheraphy treatment machine. Clinical Oncology. 2003;15(6):353-58 https://doi.org/10.1016/S0936-6555(03)00065-7

[8] Conforti D, Guerriero, Guido R, Veltri M, An Optimal decesion making approach for management of Radiotherapy patient. OR Spectrum 2011; 33(1):123-48 https://doi.org/10. 1007/s00291-009-0170-y

[9] Conforti D, Guerriero, Guido R.Optimization model for radiotherapy patient scheduling 4OR.2008;6(3):263-78 
[10] Hans EW, van Houdenhoven M, Hulshof PJH. A framework for healthcare planning and control. In: Handbook of Healthcare System Scheduling. New York: Springer; 2012. p. 303-20. https://doi.org/10.1007/978-1-4614-1734-7_12

[11] Brailsford S. overcoming the barriers to implementation of operations research simulation models in healthcare. Clin Invest Med. 2005; 28(6):312-5.

[12] West, M.A. and Lyubovnikova, J. (2013), "Illusions of team working in health care", Journal of Health Organization and Management, Vol. 27 No. 1, pp. 34-42 https://doi.org/10.1108/14777261311311843

[13] Tang, C., Xiao, Y., Chen, Y. and Gorman, P.N. (2015), "Design for supporting healthcare teams", in Patel, V.,Kannampallil, T. and Kaufman, D. (Eds) Cognitive Informatics for Biomedicine. Health Informatics, Springer, Cham, pp. 215-239. https://doi.org/10. 1007/978-3-319-17272-9_10

[14] Kuziemsky, C.E. (2015), "A model of tradeoffs for understanding health information technology implementation", Techno-Anthropology in Health Informatics: Methodologies for Improving Human-Technology Relations, Vol. 215, pp. 116-128.

[15] Ezziane, Z., Maruthappu, M., Gawn, L., Thompson, E.A., Athanasiou, T. and Warren, O.J. (2012), "Building effective clinical teams in healthcare", Journal of Health Organization and Management, Vol. 26 No. 4, pp. 428-436 https://doi.org/10.1108/14777261211251508

[16] Tang, C., Xiao, Y., Chen, Y. and Gorman, P.N. (2015), "Design for supporting healthcare teams", in Patel, V.,Kannampallil, T. and Kaufman, D. (Eds) Cognitive Informatics for Biomedicine. Health Informatics, Springer, Cham, pp. 215-239. https://doi.org/10.1007/978-3-319-17272-9 10

[17] Quan, S.D., Wu, R.C., Rossos, P.G., Arany, T., Groe, S., Morra, D., Wong, B.M., Cavalcanti, R., Coke, W. and Lau, F.Y. (2013), "It's not about pager replacement: an indepth look at the interprofessional nature of communication in healthcare", Journal of Hospital Medicine, Vol. 8 No. 3, pp. 137-143 https://doi.org/10.1002/jhm.2008

[18] Manojlovich, M., Harrod, M., Holtz, B., Hofer, T., Kuhn, L. and Krein, S. (2015), "The use of multiple qualitative methods to characterize communication events between physicians and nurses", Health Communication, Vol. 30 No. 1, pp. 61-69. https://doi.org/10.1080/10410236.2013.835894

[19] Kuziemsky, C.E. (2015), "A model of tradeoffs for understanding health information technology implementation", Techno-Anthropology in Health Informatics: Methodologies for Improving Human-Technology Relations, Vol. 215, pp. 116-128.

[20] Kellogg, K.C., Gainer, L.A., Allen, A.S., O’Sullivan, T. and Singer, S.J. (2017), “An intra organizational model for developing and spreading quality improvement innovations", Health Care Management Review, Vol. 42 No. 4, pp. 292-302 https://doi.org/10.1 097/HMR.0000000000000122

[21] Hsieh, H. and Shannon, S.E. (2005), "Three approaches to qualitative content analysis", Qualitative Health Research, Vol. 15 No. 9, pp. 1277-1288. https://doi.org/10.1 $177 / 1049732305276687$

[22] Golden, B. (2006), "Transforming healthcare organizations", Healthcare Quarterly, Vol. 10 Nos $10-9$, p. 4.

[23] Ezziane, Z., Maruthappu, M., Gawn, L., Thompson, E.A., Athanasiou, T. and Warren, O.J. (2012), "Building effective clinical teams in healthcare", Journal of Health Organization and Management, Vol. 26 No. 4, pp. 428-436 https://doi.org/10.1108/14777261211251508

[24] Eikey, E.V., Reddy, M.C. and Kuziemsky, C.E. (2015), "Collaboration and health information technologies in biomedical informatics research: a systematic review”, Journal of Biomedical Informatics, Vol. 57, October, pp. 263-277. https://doi.org/10. $\underline{1016 / j . j b i .2015 .08 .006}$ 
[25] Collins, S.A., Bakken, S., Vawdrey, D.K., Coiera, E. and Currie, L. (2011), "Model development for HER interdisciplinary information exchange of ICU common goals", International Journal of Medical Informatics, Vol. 80 No. 8, pp. e141-e149. https://doi.org/10.1016/j.ijmedinf.2010.09.009

[26] Coiera, E. (2014), "Communication spaces", Journal of the American Medical Informatics Association, Vol. 21 No. 3, pp. 414-422. https://doi.org/10.1136/amiajnl-2012-001520

[27] Coiera, E. (2006), "Communication systems in healthcare", Clinical Biochemist Reviews, Vol. 27 No. 2, pp. 89-98.

[28] Alvarez, G. and Coiera, E. (2006), "Interdisciplinary communication: an uncharted source of medical error?” Journal of Critical Care, Vol. 21 No. 3, pp. 236-242. https://doi.org/10. 1016/i.jcrc.2006.02.004

[29] Aceti, V. and Luppicini, R. (2013), "Exploring the effect of mhealth technologies on communication and information sharing in a pediatric critical care unit: a case study", in Tan, J. (Ed.), Healthcare Information Technology Innovation and Sustainability: Frontiers and Adoption, IGI Global, Hershey, PA, pp. 88-108. https://doi.org/10.4018/978-1-46662797-0.ch006

[30] Hecker, M.T., Aron, D.C., Patel, N.P., Lehmann, M.K. and donskey, C.J. (2003), "Unnecessary use of antimicrobials in hospitalized patients: current patterns of misuse with an emphasis on the antianaerobic spectrum of activity", Archives of Internal Medicine, Vol. 163 No. 8, pp. 972-978. https://doi.org/10.1001/archinte.163.8.972

[31] King, L. (2014), "Antibiotic use and resistance: moving forward through shared stewardship", white paper-Antibiotic Use and Resistance: Moving Forward Through Shared Stewardship from proceedings of the National Institute of Animal Agriculture Antibiotics Symposium, Atlanta, GA, November 12-14, p. 9.

[32] Magill, S.S., Edwards, J.R., Bamberg, W., Beldavs, Z.G., Dumyati, G., Kainer, M.A., Lynfield, R., Maloney, M., McAllister-Hollod, L., Nadle, J., Ray, S.M., Thompson, D.L., Wilson, L.E. and Fridkin, S.K. (2014), "Multistate point-prevalence survey of health careassociated infections", New England Journal of Medicine, Vol. 370 No. 13, pp. 11981208. https://doi.org/10.1056/NEJMoa1306801

[33] Pittenger, K., Williams, B.L., Mecklenburg, R.S. and Blackmore, C.C. (2015), "Improving acute respiratory infection care through nurse phone care and academic detailing of physicians", Journal of the American Board of Family Medicine, Vol. 28 No. 2, pp. 195204. https://doi.org/10.3122/jabfm.2015.02.140197

[34] Pollack, L.A. and Srinivasan, A. (2014), "Core elements of hospital antibiotic stewardship programs from the centers for disease control and prevention", Clinical Infectious Diseases, Vol. 59 No. S3, pp. S97-S100. https://doi.org/10.1093/cid/ciu542

[35] Sneeringer, S., MacDonald, J., Key, N., McBride, W. and Mathews, K. (2015), "Economics of antibiotic use in US livestock production", Economic Research Report No. 200, US Department of Agriculture, Economic Research Service, Washington, DC, November.

\section{Authors}

Dr. Mohammad Rashid Hussain, Assistant Professor, Department of Information Systems, College Of Computer Science, King Khalid University, Abha, Kingdom of Saudi Arabia, received his Master of Technology degree from the Department of Computer Science \& Engineering, Anna University, Chennai, India. After that he obtained his PhD degree from Bihar University, India. He was an Associate Professor 
in the Department of Computer Science \& Engineering, ABESIT Ghaziabad, India. $\mathrm{He}$ is currently working as an Assistant Professor in the department of Information Systems, King Khalid University, Abha, Saudi Arabia. His research interests include Computer Networks, Information Technology and Operation Research. Email id: humohammad@kku.edu.sa

Mohammad Equebal Hussain, Received Master of Technology in Computer Science from Indian Statistical Institute, Kolkata, West Bengal, India in 2002. His research interests include cloud computing, hypervisor-based security, wireless network security, IoT and operation research. Currently he is pursuing Ph.D in Computer Science from Suresh Gyan Vihar University (SGVU) Jaipur, Rajasthan, India. Prior to joining Ph.D, he worked as a Lecturer in Galgotia's College of Engineering and Technology, Greater Noida, UP. India. He also has experience of software development in various multinational companies. He has published some papers in wireless sensor network, virtualization, cloud computing, and wireless sensor network security. Email id: mdequebal.60508@mygyanvihar.com

Article submitted 2019-01-10. Resubmitted 2019-02-27. Final acceptance 2019-01-27. Final version published as submitted by the authors. 